\title{
Framework for Digital Development in Industrialized Housebuilding
}

\author{
Martin LENNARTSSON ${ }^{\mathrm{a}, 1}$, Ibrahim YITMEN ${ }^{\mathrm{a}}$, Hamid MOVAFFAGHI ${ }^{\mathrm{a}}$, and Henrik \\ LINDEROTH $^{\mathrm{a}}$ \\ a Jönköping University, Jönköping, Sweden
}

\begin{abstract}
Building Information Modelling (BIM) is claimed to transform the Architecture, Engineering and Construction (AEC) industry, whereas current research has argued that diffusion of BIM use proceeds at a slower rate than the optimistic predictions. Despite that potential of BIM is higher in industrialized housebuilding, the trade express similar characteristics as traditional construction both in terms of BIM sue but also organization of assets. The aim of this paper is to present a conceptual framework for digital development in industrialized timber housing. Data were gathered from eight industrialized housebuilding companies in a mixed approach with interviews, focus groups and a survey. The analysis presents the current use of BIM and digital tools and prioritized development areas within this domain. By adding a theoretical overview of current research for industrialized housebuilding with focus on platform strategies and digital development a framework is drawn. Problems with transfer in the interfaces between software were emphasized. Current research on developing a system for Product Lifecycle Management (PLM) in industrialized housebuilding indicate a path forward. A PLM system facilitates the development of digital developments such as digital twins and smart products, which possess the potentials to generate crucial feedback, which is crucial for the competitiveness and efficiency of industrialized housebuilding. Thus, for a trade with high levels of complexity, a move towards a fully functional PLM system might not only be desirable but decisive.
\end{abstract}

Keywords. Building Information Modelling, Industrialized housebuilding, Information transfer, Product Lifecycle Management

\section{Introduction}

Researchers and practitioners seem to agree on Building Information Modelling (BIM) and its potential applicability in, and benefits for, construction [1]. BIM is claimed to transform the Architecture, Engineering and Construction (AEC) industry, whereas current research has argued that diffusion of BIM use proceeds at a slower rate than the optimistic predictions. The construction sector is still characterized from heterogenous projects and fragmentation [2]. In a study on BIM use among medium-sized contractors in Sweden [3], the identified major perceived constraints were the lacking demand from clients and that that trading partners did not use BIM. Instead, implementation was determined by an individual's subjective positive or negative evaluation of BIM.

Research in the UK points out industrialized housebuilding and BIM to facilitate productivity $[4,5]$ and that the potential of BIM is greater within industrialized housebuilding than for traditional construction. According to Gosling and Naim [6],

\footnotetext{
${ }^{1}$ Corresponding Author. [martin.lennartsson@ju.se]
} 
construction is described as an Engineer-to-Order-sector. Thus, much time and effort are spent in design [7]. Persson et al. [8] identified problems related to information management in industrialized housing design and production, e.g. the lack of interoperability between software. Missing product documentation, undefined processes and IT support were identified as obstacles to effective industrialized housebuilding [9]. Integration of the whole value chain has been put forward as primary key to success [10]. Successful industrialized housebuilding is built on effective information exchange between supply chains, which requires efficient information management [11].

The aim of this paper is to present a conceptual framework for digital development in industrialized housebuilding. This is accomplished by gathering data from eight industrialized housebuilding companies and presenting the current use of BIM and digital tools and prioritized development areas within this domain. By adding a theoretical overview of current research for industrialized housebuilding with focus on platform strategies and digital development a framework is drawn. A mixed method approach was chosen. First, interviews with technical mangers from eight industrialized housebuilders were conducted, a survey was administered to 17 major industrialized house-building companies on the Swedish market and two focus group sessions with the technical managers were held to identify prioritized development areas.

\section{Method}

To describe a state of practice and outline a framework, empirical data were gathered from eight companies. The selected methods were interviews, survey and focus groups. A group with technical managers from eight industrialized housebuilding companies (table 1) were interviewed to investigate their market situation, the information flow in the sales, production and delivery processes, and how BIM is used in these processes. Succeeding the interview study, a survey was conducted. The aim of the survey was to explore the extent of BIM use among industrialized house builders, as well as to explore perceived barriers and driving forces for BIM use. The data was collected via a webbased survey. A focus group containing the technical managers then tried to identify BIM-related issues that would be beneficial for the group of companies to further develop. At the second occasion, supply chain challenges were scrutinized.

Table 1. The companies and their segments as well as respondents' positions in the company

\begin{tabular}{ccc}
\hline Company & Segment & Respondent(s) \\
\hline Alpha & Single family homes & Admin. Manager, Tech. manager \\
Beta & Single family homes & Technical manager \\
Gamma & Single family homes & Development manager \\
Delta & Single family homes & Structural manager \\
Epsilon & Single family homes & Technical managers x2 \\
Zeta & Single family homes & Development manager, Designer \\
Eta & Multifamily buildings & R \& D managers x2 \\
Theta & Public buildings & CEO and technical manager \\
\hline
\end{tabular}

\section{Theoretical framework}

Industrialized housebuilding is moving towards an enhanced production where management of information along the value chain is critical in order to deliver housing projects on time and with the desired quality [12]. A move towards industrialized 
housebuilding means a shift from strictly project-based production to a more processoriented production [13], where the production system is process-oriented with defined value streams, repetitive operations and experience feedback [7]. Competitiveness is driven from factors such as flexibility, delivery time predictability, quality level and cost $[14,15]$. Consequently, a key element within this sector is information management, i.e. with repetitive production the process is more vulnerable to erroneous information. Thus, industrialized housebuilding companies are moving towards an enhanced production where management of information along the value chain is critical to deliver housing projects on time and with the desired quality [16].

Currently, digital tools and systems are used in both design and production to produce, deliver and instruct actors throughout the phases of a project [16]. The supply chain is long and fragmented [13]. ICT-solutions, such as BIM, can mitigate this condition [17]. Jonsson and Gosling [18] argue that production systems using higher degree of off-site assembly also have a higher extent of ICT-solutions. Constructs that constitute industrialized housebuilding includes management of components, processes and relations in the standardization of housebuilding platforms, as well as development of ICT for integration [16]. Jonsson and Gosling [18] also points out that product standardization facilitates ICT-solutions such as BIM.

\subsection{Platform strategies}

In recent years, there has been an increasing focus on the platform concept in industrialized housing [19-21]. Product platforms embody an intent to reuse knowledge in transforming customer demands over to functional requirements and design parameters in a product [22]. Through product platforms, companies achieve high levels of product variety, reduced time to market, improved operational efficiency and responsiveness to market needs [23, 24]. Improved customer value is targeted by adaptation of product solutions and swift introduction of new technologies combined with cost-efficiency and lead-time reduction. The use of a product platform, where external and internal efficiency are well balanced, has been acknowledged as a strategic enabler for mass customization and increased competitiveness. Ulrich [25] describes the product architecture as: the arrangement of functional elements; the mapping from functional elements to physical components; the specifications of the interfaces among interacting physical components. Thus, the product architecture facilitates the design work with functions of components and the topology of interfaces. Interface management contributes to shorten the time to market and commonality in interface definitions before component development encourage greater innovation on component level in the development process [26]. The interface definitions become central for how modules could be upgraded between products [27]. Another reason for introducing modules is to support standardization of solutions - the same solution is always used for economy of scale, reduce the lead-time in development and/or ensure even quality. A third reason is to support the formation of a product family where a set of product variants can be provided targeting different markets or customers while efficiency in purchasing, production, aftersales etc. can be kept at a competitive level. Modularization is regarded as the foundation of product platforms and configuration to support customization [28]. Whatever the predefinition rate is, it is difficult to categorize. Different housing offers completely different types of products, but each offer must be analyzed against which production system the contractor uses [29]. Reusing processes and technical solutions with components lead to the formation of predefinitions in housebuilding platforms for 
products and processes [30]. Predefinitions has demonstrated how to speed up production with better control and productivity in flow-oriented organizations. The life cycle information flow through for industrialized housebuilders is of interest, specifically how to track objects in production.

\subsection{Digital development in industrialized housebuilding}

Mukkavaara [12] stresses that the complexity of the design process and the disperse number of different actors implies the improbability of a holistic BIM software capable of managing all demands. Consequently, manual transfer between different software is necessary. State of practice in industrialized house building displays disorganized management of assets [21]. Modular product architecture is not supported by aligning processes and management of assets. New projects are generated from the creation of new variants instead of re-use of previous solutions, revealing poor awareness of the building system and knowledge within the company.

The Design Platform (DP) [31] was created as a response to the lack of platform models for ETO companies; especially to increase the reuse of company assets in environments where requirements fluctuate during the development. A Design Platform is composed of different objects related to Process, Synthesis Resources, Product Constructs, Assessments Resources, Solutions and Projects. These objects can be, but are not limited to, components and modules since reuse can often be found on a higher level of abstraction than geometry. When the possibility of reusing geometry is scarce, guidelines, process descriptions, calculations etc. can be associated with the type of generic product item (part or assembly) they concern. This creates a coherent platform description consisting of heterogeneous assets which can evolve over time and enables reuse. André et al. [32] has explored the Design Platform in an industrialized housebuilding case and results shows that the currently used standard solutions are following a generic construction process rather than the product architecture. However, the study presents a path forward to introduce a Product Lifecycle Management (PLM) system by reorganizing the solutions in accordance with the object definitions from the design platform approach. For a working PLM system, meta data and Bill of Materials (BOM) management is crucial [33]. Also, Boton et al. [2] stress that product structure is the missing link in the BIM approach.

Furthermore, with the use of product platforms and a product-oriented perspective, predefined solutions could benefit from using alternative structures, such as the Modular BOMs, in efforts to more efficiently derive products [12]. Jansson [34] continues this track and applies BOMs to breakdown the product structure and untangle the inherent knowledge, to improve digital communication between information systems in industrialized housebuilding. The concept of implementing BOMs in the context of industrialized house builders is showing promise in the search for methods where information is structured in the IT-systems throughout the value chain. Its use in the manufacturing industry is described by previous research but in the context of industrialized house-building it is novel. Identifying the owner(s) and user(s) of BOMs, in order to know who defines them and how they are consumed; what different representations of BOMs (e.g. E-BOM, M-BOM) could be used and how they should be structured; how BOMs could be used to bridge IT-systems (e.g. BIM and PLM) in order to support design and production of timber houses are the potential research areas [16]. 


\subsection{Potentials for moving towards PLM in Industrialized housebuilding}

The concepts of Digital Twin (DT) and real-time simulation has the potential to increase understanding of the benefits and impacts that industrialized house builders face when applying real-time simulation and understand where the transformation should start with PLM, i.e. PLM is an integrative information-driven approach comprised of people, processes/practices, and technology to all aspects of a product's life and its environment, from its design through manufacture, deployment and maintenance. The implementation of a real time simulation-based DT will change way industrialized timber house builders view their products. The virtual product becomes the asset that opens new business opportunities, for example, connected information-based services, enabling the creation of Product-Service-Systems (PSS) that can be used to simulate the PSS different lifecycle phases [35]. The PLM system provides functional and architectural information, while DT brings real-time information to a model This is why the application of DT gains momentum with technical progress in Internet of Everything (IoE). IoE provides a solution to bring PLM to a next level. More insights and experience from observing the product in the field will establish a feedback loop from user to producer. Producers can adjust the product while it is in use by the customer. Major changes and decisions for the product become obvious. The DT has the potential to significantly change methods and tools in every phase of the PLM [36].

The increasing complexity of products, processes and organizations further underline the importance of PLM to facilitate information management. The introduction of the concept of The Fourth Industrial Revolution or Industry 4.0 intensifies this increase in complexity [37]. Smart-connected technologies, such as IoE and cloud computing, are transforming how industries and enterprises do business by improving the lifecycle management of their product. IT is becoming an integral part of complex products in smart-connected environments; these have now evolved into Smart Connected Products (SCPs). SCPs significantly influence traditional PLM, allowing for product development collaboration, intelligent manufacturing facilitation, and customized service provision. With business environment and manufacturing enterprise structures rapidly evolving, IT is considered a strategic resource and there are new functional requirements associated with SCPs. In this next step, Internal and external operational activities of PLM should be redefined, including product development, manufacturing, customer relationship management, marketing, sales, services, human resources management, financial control, and cultural governance [38].

The customized timber building can be automatically decomposed into modular products and work packages through BIM in construction industry 4.0 which is used to generate the smart Prefabrication Housing Production objects (SPOs) and smart work packages with the support from IoTs. The logistics (e.g., transportation) in construction industry 4.0 has already involved georeferencing on a GIS platform to trace the materials and prefabricated products and predict the delivery time based on the spatial routing network analysis. Robots and autonomous machines, the necessary elements of the construction industry 4.0, which are well connected to the new generation BIM platform, will be widely used in plants and on construction sites. These are also the essential supporting technologies to achieve adaptivity, sociability, autonomy, and awareness of SPOs and Smart Work Packages (SWPs). Mass customization which combines the flexibility, adaptivity, and personalization with low unit costs associated with mass production is one of the final objectives of construction industry 4.0 [39]. 


\subsection{Summary}

When synthesizing the presented domains of industrialized housebuilding, the conclusion is that the trade is not getting the full potential from a platform strategy. Knowledge capture is poorly organized and obstructs a uniform way of working. Still, the factories in industrialized housebuilding is working as a prerequisite in the business strategy and management of standard parts is therefore necessary. As industrialized housebuilding originating in traditional on-site construction, which follows a waterfall process principle and continuous demand changes, a platform strategy is not always feasible. As Abanda et al. [5] points out, information flows and quality are more important for industrialized housebuilding and from that perspective, a PLM system and platform strategy is a logic path forward. Both $[32,34]$ demonstrate the possibility to organize predefinitions and assets in a way that facilitates a PLM system. An operational PLM system would function as the backbone for development of other digital tools and solutions, such as digital twins and smart houses.

\section{Empirical data analysis and framework}

The interviews with the technical managers (table 2) demonstrated that suitability and benefit of different BIM applications, visualization for customers (customer view), 3D modelling in design and engineering (design view) and different types of analysis and simulations are perceived to have the biggest potential. Simulations such as clash control, perceived from two of eight companies, to have the potential for implementation especially for complex structures such as schools and multi-family houses.

Table 2. Summary of interviews regarding BIM applications in functional areas.

\begin{tabular}{|c|c|c|c|c|c|c|c|c|}
\hline Companies & Alpha & Beta & Gamma & Delta & Epsilon & Zeta & Eta & Theta \\
\hline \multicolumn{9}{|l|}{ Marketing and Sales } \\
\hline $\begin{array}{l}\text { Visualization } \\
\text { (customer view) }\end{array}$ & $\bullet$ & $\bullet$ & $\bullet$ & $\bullet$ & $\bullet$ & $\bullet$ & $\bullet$ & $\bullet$ \\
\hline \multicolumn{9}{|c|}{ Design and Engineering } \\
\hline Modelling, BIM $3 D$ & $\bullet$ & $\bullet$ & $\bullet$ & $\bullet$ & $\bullet$ & $\bullet$ & $\bullet$ & $\bullet$ \\
\hline Simulation & $\bullet$ & $\bullet$ & $\bullet$ & $\bullet$ & $\bullet$ & $\bullet$ & $\bullet$ & $\bullet$ \\
\hline Clash control & $\bullet$ & & & & & & & $\bullet$ \\
\hline \multicolumn{9}{|l|}{ Product } \\
\hline \multicolumn{9}{|l|}{ Production } \\
\hline $\begin{array}{l}\text { Master Production } \\
\text { Schedule (MPS) }\end{array}$ & & & & & & & $\bullet$ & $\bullet$ \\
\hline Cost est. BIM 5D & $\bullet$ & $\bullet$ & $\bullet$ & $\bullet$ & $\bullet$ & & $\bullet$ & $\bullet$ \\
\hline $\begin{array}{l}\text { Assembly instruction } \\
\text { (site view) }\end{array}$ & & & & $\bullet$ & & & & \\
\hline $\begin{array}{l}\text { Product Data } \\
\text { Management (PDM) }\end{array}$ & & & & & & & & $\bullet$ \\
\hline $\begin{array}{l}\text { Process planning } \\
\text { (process view) }\end{array}$ & $\bullet$ & $\bullet$ & & $\bullet$ & $\bullet$ & $\bullet$ & $\bullet$ & $\bullet$ \\
\hline $\begin{array}{l}\text { Enterprise Resource } \\
\text { Planning }(E R P)\end{array}$ & $\bullet$ & $\bullet$ & $\bullet$ & $\bullet$ & & $\bullet$ & $\bullet$ & $\bullet$ \\
\hline
\end{tabular}


There are ambitions to integrate BIM applications with ICT tools such as Master Production Schedule (MPS), Product Data Management (PDM) and Enterprise Resource Planning (ERP) within production. ICT-tools were primarily developed for automating routine tasks, while BIM is a system for information exchange between members of two or more organizations. One problem emerging from the interviews is the lack of interfaces between BIM applications and other ICT tools like MPS, PDM and ERP.

The survey demonstrated that BIM use is still rather rudimentary where visualization in the detailed design were both judged as most frequently used and also most useful. Clash controls, visualization for users, quantity estimation and communication with parties were also given high scores on usefulness. However, for perceived driving forces of BIM (table 3), less errors and misunderstandings, facilitation to document and transfer information about a building and quality were on top. Notably, the largest constraint perceived was investments in hardware and software. Further, largest challenges for BIM use were focusing on cultural changes and collaboration with different partners.

Table 3. Perceived driving forces for BIM use. Scale from 1 (totally disagree) to 5 (totally agree).

\begin{tabular}{|c|c|c|c|}
\hline Rank & & Mean & SD \\
\hline 1 & $\begin{array}{l}\text { Use of BIM can lead to less errors and } \\
\text { misunderstandings }\end{array}$ & 4.28 & 0.716 \\
\hline 2 & $\begin{array}{l}\text { BIM facilitates to document and transfer information } \\
\text { about a building }\end{array}$ & 4.08 & 0.712 \\
\hline 3 & BIM can improve the quality of my work & 4.07 & 0.985 \\
\hline 4 & $\begin{array}{c}\text { By using BIM, we can follow the technical } \\
\text { development }\end{array}$ & 3.93 & 0.985 \\
\hline 5 & BIM gives the company competitive advantages & 3.88 & 1.067 \\
\hline
\end{tabular}

The first focus group session tried to identify BIM-related issues that would be beneficial for the group of companies to further develop. The group structure with technical managers, yielded that most topics concerned technical issues. The major topics discussed were the need for a seamless information flow, in concrete, to replace paper drawings with digital information, the need for integration of data from the BIM-model to other systems like ERP, and the need for standardization component data. The need for a translator between BIM-objects and a component database was raised. The group also discussed the possibility to connect company specific structures for components to national standards for timber construction. The purpose would then be to link the management of articles and components for the companies to standards, to make design, procurement, material management, information flows and facility management more efficient and in the future also include assessment of environmental impact from the components.

In the other focus group supply chain challenges were scrutinized. The discussions brought up issues regarding interface management and more specifically, coordination, establishment of routines and time planning, long-term collaboration and building trust among your suppliers as well as utilizing the knowledge repository buried in the subcontractors and suppliers. Further, costs are derived from poor supply chain management, which yields better collaboration and designation of a logistics manager. On-site management is poor and demand-driven deliveries and total cost analysis were called for. All these research results from construction management has presented the strengths and benefits from BIM and digitalization but still the implementation pace is slow. Thus, more effort should be put on changing habits and poor routines, which has been acknowledged as a barrier to innovation in construction. The overall holistic 
analysis of the gathered data describes the state of practice showing similarities with the traditional construction sector, i.e. digitalization is immature and not reaching its potential. The survey displayed a need for better connection with the ERP. Information transfer in the interfaces was raised by the technical managers both from the interviews and also from the focus groups which has also been stressed by [12]. Interface management is crucial in the execution of a platform strategy [27].

Two tracks were identified linked to the focus on seamless information flows, BIMsupport in the supply chain and production without drawings. When combining these suggestions and the initiatives [32,34] on PLM in industrialized housebuilding, the suggested framework (fig.1) is to work towards PLM development and alignment with the platform strategy.

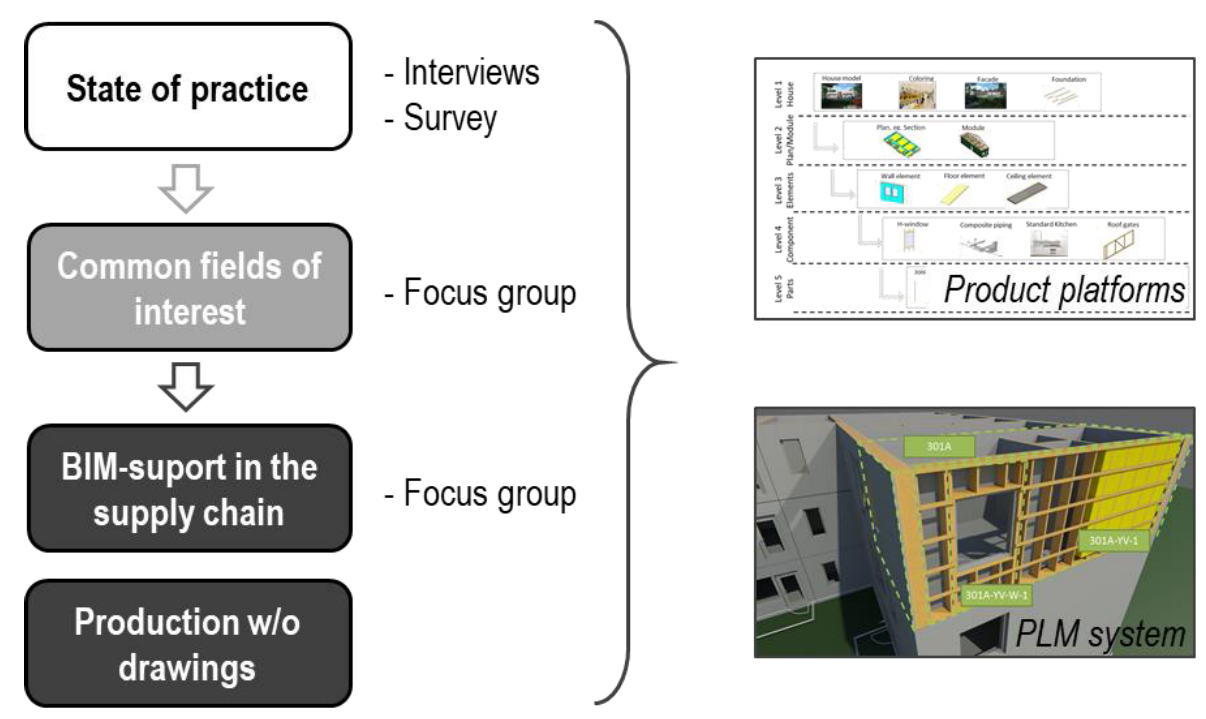

Figure 1. Framework for digital development in industrialized housebuilding.

\section{Discussion and conclusion}

Reflection on the gathered data show that use, benefits and challaneges regarding BIM are shared with the view in traditional construction [3, 40]. [32] adds to this view where assets at industrialised housebuilders are still categorised in accordance with the guilds in traditional construction rather than a platform based product architecture. When analyzing the potentials for moving towards PLM in industrialized housebuilding combined with the presented framework, implementing a fully functional PLM system may not only be desired but decisive. The increasing complexity and platform strategy result in demand for precise management of information and knowledge. Otherwise, traditional companies will have more flexible organizations and will cope better than industrialized housebuilders. Thus, developing middleware to facilitate information transfer in the software interfaces will be key to solve. Further, as the presented potentials demonstrate, a PLM system can provide solutions (digital twins, smart products) which will supply industrial housebuilding with more feedback and prepare for the construction 
industry 4.0. A schematic overview is presented in fig. 2, where the Construction Industry 4.0 being a fundamental challenge in terms of automated production and digitalization level in industrialized housebuilding, offers connected environments with the use of IoE involving the production of customized products (building components) assembled for smart products (smart houses). Prerequisites for Construction Industry 4.0 to be successful is the creation of a digital twin of a building. BIM with consistent and structured data management is the key to generate such a digital building whose dynamic performance can be developed by building simulation tools for a variety of different boundary conditions. Sensors distributed throughout the manufacturing process create signals enabling the twin to capture operational and environmental data pertaining to the physical process in the real world. Real-world operational and environmental data from the sensors are aggregated and combined with data from the enterprise, e.g. BOMs which is a detailed recipe and decomposition of the product within the context of industrialized housebuilding. Digital twin's ability to link large amounts of data to fast simulation makes it possible to perform real-time optimization of products and production processes. Along the PLM from design to construction, operation and maintenance towards remodeling or demolition, the digital twin follows all modifications of the real building and dynamically readjusts itself in case of recorded performance differences. Thus, for the whole life span of the real building, performance predictions generated with the virtual twin represent an accurate basis for well-informed decisions.

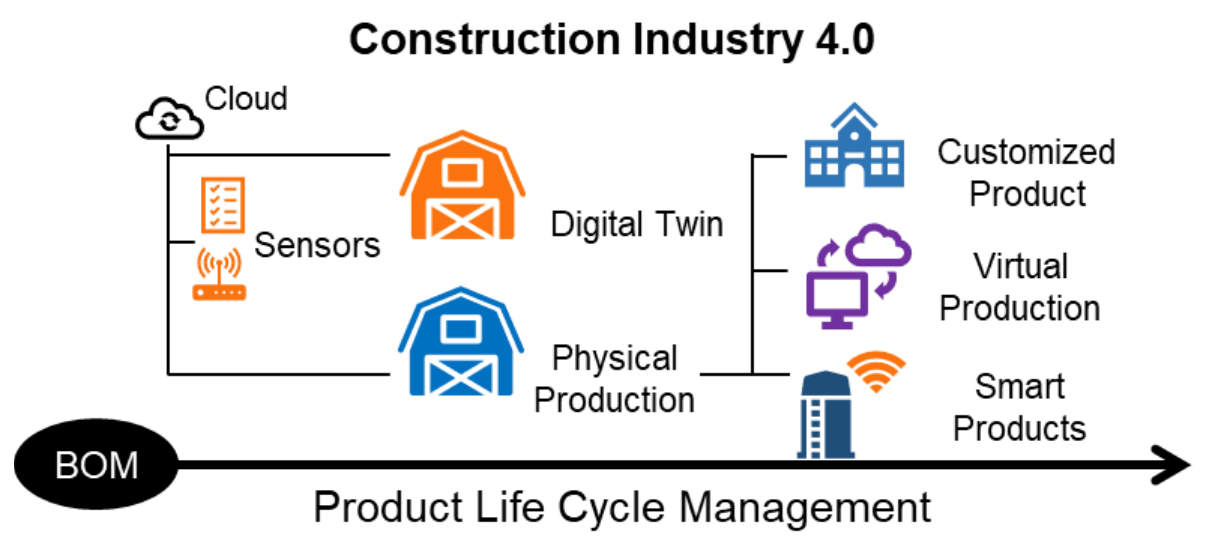

Figure 2. Path forward for digital development in industrialized housebuilding.

The aim of this paper was to present a framework for information transfer in industrialized timber housing. The result is based on an analysis of data regarding current use of BIM and digital tools in industrialized housebuilding and also scrutinizing current initiatives regarding PLM development and the link to solutions such as digital twins and smart products. For a trade with high levels of complexity, a move towards a fully functional PLM system might not only be desirable but decisive.

\section{Acknowledgement}

The authors are grateful to the participating companies and the respondents of the survey as well as the innovation environment of Smart Housing Småland for financial support. 


\section{References}

[1] S. Lee, and J. Yu, Comparative Study of BIM Acceptance between Korea and the United States, Journal of Construction Engineering and Management, vol. 142, no. 3, pp. 05015016, 2016/03/01, 2016.

[2] C. Boton, L. Rivest, D. Forgues, and J. Jupp, Comparing PLM and BIM from the Product Structure Standpoint, Product Lifecycle Management for Digital Transformation of Industries. pp. 443-453.

[3] P. Bosch-Sijtsema, A. Isaksson, M. Lennartsson, and H. Linderoth, Barriers and Facilitators for BIM Use among Swedish Medium-Sized Contractors : We Wait Until Someone Tells us to Use it, Visualization in Engineering, vol. 5, no. 3, pp. 1-12, 2017, 2017.

[4] J. Goulding, F. Rahimian, M. Arif, and M. Sharp, Offsite Construction: Strategic Priorities for Shaping the Future Research Agenda, Architectoni.ca, vol. 1, no. 1, pp. 62-73, 2012.

[5] F. H. Abanda, J. H. M. Tah, and F. K. T. Cheung, BIM in Off-site Manufacturing for Buildings, Journal of Building Engineering, vol. 14, pp. 89-102, 2017/11/01/, 2017.

[6] J. Gosling, and M. M. Naim, Engineer-to-order Supply Chain Management: A Literature Review and Research Agenda, International Journal of Production Economics, vol. 122, no. 2, pp. 741-754, 2009.

[7] H. Johnsson, and J. H. Meiling, Defects in Offsite Construction: Timber Module Prefabrication, Construction Management and Economics, vol. 27, no. 7, pp. 667-681, 2009/07/01, 2009.

[8] S. Persson, L. Malmgren, and H. Johnsson, Information Management in Industrial Housing Design and Manufacture, Journal of Information Technology in Construction (ITcon), vol. 14, pp. 110-122, 2009, 2009.

[9] B. Hjort, J. Lindgren, B. Larsson, and S. Emmit, Success Factors Related to Industrialized Building in Sweden, in International Conference on Construction in a Changing World, 4-7 May, 2014, Dambulla, Sri Lanka, Salford, 2014.

[10] J. Lessing, Business Models for Product-oriented House-Building Companies - Experience from Two Swedish Case Studies, Construction Innovation, vol. 15, no. 4, pp. 449-472, 2015.

[11] L. Alvarez-Anton, M. Koob, J. Diaz, and J. Minnert, Optimization of a Hybrid Tower for Onshore Wind Turbines by Building Information Modeling and Prefabrication Techniques, Visualization in Engineering, vol. 4, no. 1, pp. 3, 2016/01/08, 2016.

[12] J. Mukkavaara, Structures for Supporting BIM-based Automation in the Design Process, Licentiate thesis, comprehensive summary, Licentiate thesis / Luleå University of Technology, Luleå University of Technology, Luleå, 2018.

[13] H. Jonsson, Production Strategy in Project Based Production within a House-Building Context: Linköping University Electronic Press, 2017.

[14] E. Söderholm, and H. Johnsson, Housing Design Performance - How is it Measured?, in Annual ARCOM Conference : 07/09/2009 - 09/09/2009, Reading, 2009, pp. 281-290.

[15] H. Jonsson, and M. Rudberg, Classification of Production Systems for Industrialized Building: a Production Strategy Perspective," Construction Management and Economics, vol. 32, no. 1-2, pp. 53-69, 2014.

[16] J. Mukkavaara, G. Jansson, and T. Olofsson, Structuring Information from BIM : A Glance at Bills of Materials, in 35th International Symposium on Automation and Robotics in Construction (ISARC 2018), Berlin, July 20-25 2018, 2018, pp. 362-368.

[17] S. Dehlin, and T. Olofsson, An Evaluation Model for ICT Investments in Construction Projects, Electronic Journal of Information Technology in Construction, vol. 13, pp. 343-361, 06/01, 2008.

[18] H. Jonsson and J. Gosling, Information Exchange in House-building - a Production Strategy Perspective, in 24th EurOMA conference, Edinburgh Scotland, 2017.

[19] H. Johnsson, Production Strategies for Pre-engineering in House-building: Exploring Product Development Platforms, Construction Management and Economics, vol. 31, no. 9, pp. 941-958, 2013.

[20] G. Jansson, Platforms in Industrialised House-building, Luleå tekniska universitet, 2013.

[21] M. Lennartsson, and F. Elgh, Exploring Product Development in Industrialized Housing to Facilitate a Platform Strategy. In IGLC26, Chennai, India, 2018, pp. 538-548.

[22] M. H. Meyer, and A. P. Lehnerd, The Power of Product Platforms - Building Value and Cost Leadership, New York: The Free Press, 1997.

[23] M. H. Meyer, and J. M. Utterback, The Product Family and the Dynamics of Core Capability, Sloan management review, vol. 34, no. 3, pp. 29-47, 1993.

[24] M. Muffatto, Introducing a Platform Strategy in Product Development, International Journal of Production Economics, vol. 60-61, no. 1, pp. 145-153, 1999.

[25] K. Ulrich, The Role of Product Architecture in the Manufacturing Firm, Research Policy, vol. 24, no. 3, pp. 419-440, 1995/05/01/, 1995.

[26] G. Erixon, Modular Function Deployment: A Method for Product Modularisation: Royal Inst. of Technology, Department of Manufacturing Systems, Assembly Systems Division, 1998. 
[27] C. Y. Baldwin, and K. B. Clark, Managing in an Age of Modularity, Harv Bus Rev, vol. 75, no. 5, pp. 84-93, Sep-Oct, 1997.

[28] L. Hvam, N. H. Mortensen \& J. Riis, Product customization: Springer Publ., 2008.

[29] M. Rudberg, and J. Wikner, Mass Customization in Terms of the Customer Order Decoupling Point, Production Planning \& Control, vol. 15, no. 4, pp. 445-458, 2004/06/01, 2004.

[30] G. Jansson, H. Johnsson, and D. Engström, Platform Use in Systems Building, Construction Management and Economics, vol. 32, no. 1-2, pp. 70-82, 2014/02/01, 2014.

[31] S. André, F. Elgh, J. Johansson, and R. Stolt, The Design Platform-a Coherent Platform Description of Heterogeneous Design Assets for Suppliers of Highly Customised Systems, Journal of Engineering Design, pp. 1-28, 2017.

[32] S. André, M. Lennartsson, and F. Elgh, Exploring the Design Platform in Industrialized Housing for Efficient Design and Production of Customized Houses, in 26th ISTE International Conference on Transdisciplinary Engineering, held at the University of Tokyo, Kashiwa Campus, July 30 - August 1, 2019, Japan, Amsterdam, 2019, pp. 125-134.

[33] J. R. Jupp, Incomplete BIM Implementation: Exploring Challenges and the Role of Product Lifecycle Management Functions, Product Lifecycle Management for Society. pp. 630-640.

[34] G. Jansson, J. Mukkavaara, F. Elgh, M. Lennartsson, Breakdown Structure in the Digitalization of Design Work for Industrialized House-Building: A Case Study of Systems Building Using Predefinition Levels of Product Platforms, in ICCREM Banff, Canada, 2019.

[35] I. Donoghue, L. Hannola, J. Papinniemi, and A. Mikkola, The Benefits and Impact of Digital Twins in Product Development Phase of PLM. in: Product Lifecycle Management to Support Industry 4.0, 2018, pp. $432-441$.

[36] C. Voell, P. Chatterjee, A. Rauch, and J. Golovatchev, How Digital Twins Enable the Next Level of PLM - A Guide for the Concept and the Implementation in the Internet of Everything Era. in: Product Lifecycle Management to Support Industry 4.0, 2018, pp. 238-249.

[37] K. Menon, H. Kärkkäinen, T. Wuest, and J. P. Gupta, Industrial Internet Platforms: A Conceptual Evaluation from a Product Lifecycle Management Perspective, Proceedings of the Institution of Mechanical Engineers, Part B: Journal of Engineering Manufacture, vol. 233, no. 5, pp. 1390-1401, 2019/04/01, 2018.

[38] Q. Zhang, X. Lu, Z. Peng, and M. Ren, Perspective: A Review of Lifecycle Management Research on Complex Products in Smart-connected Environments, International Journal of Production Research, vol. 57, no. 21, pp. 6758-6779, 2019/11/02, 2019.

[39] X. Li, G. Q. Shen, P. Wu, and T. Yue, Integrating Building Information Modeling and Prefabrication Housing Production, Automation in Construction, vol. 100, pp. 46-60, 2019/04/01/, 2019.

[40] M. Lennartsson, H. Movaffaghi, and H. Linderoth, Exploration of the BIM Development and Application : Identifying Key Areas for the Industrialized House-Building Sector, in: 17th International Conference on Computing in Civil and Building Engineering, ICCCBE2018, Tampere, Finland, June 57, 2018., 2018, pp. 1030-1037. 